\title{
MANUEL RICHARD. POR UNA SOCIOLOGÍA DESDE LAS FRONTERAS
}

Ma Luisa Gallardo*

\begin{abstract}
"El sujeto es, en primer lugar, un individuo, una frontera que separa del resto: un límite topo-cronológico que separa un interior pasado de un exterior-futuro. El interior-pasado es la parte del medio ya incorporada, el exterior-futuro es la parte del medio por incorporar"
\end{abstract}

Una sola frontera le quedaba aún por cruzar, la más incierta; sobre la patera de Caronte navega suavemente, a través de las procelosas aguas del incierto humedal. En la otra orilla, jóvenes sociólogos caminan con "la antorcha" que Comte encendiera dos siglos atrás.

Hablar de Manuel Richard, cuando ya no puedo esperar su conversación emotiva, cercana, trepidante a la vuelta de la lectura, se convierte en tarea difícil, más cuando todo sucede de modo tan inesperado en persona que espera tanto de la vida. Manuel Richard durante los últimos años, antes de alcanzar el otro estadio comtiano, publicó un estudio sobre la realidad social de las personas extranjeras en la provincia de Ciudad Real, Inmigrantes en La Mancha (Biblioteca Añil, 2002), donde ponía de manifiesto su interés por la justicia social. Señalaba la importancia del fortalecimiento de la cohesión social y la participación ciudadana para potenciar el multiculturalismo. Con este libro Manuel Richard se sumó al compromiso de apostar por la viabilidad humana

* Socióloga, Vicepresidenta de la Asociación Castellano-Manchega de Sociología y vocal por la provincia de Ciudad Real 
de un proyecto que promociona el respeto a la biodiversidad cultural y que apuesta por la construcción de un modelo de sociedad donde se integren los colectivos que actualmente son víctimas de agresiones en todos los órdenes de la vida cotidiana, desposeídos de sus derechos sociales. La metodología utilizada en su análisis compagina métodos cualitativos y técnicas cuantitativas, que favorece los aspectos emocionales y permite profundizar en las opiniones que el colectivo de personas extranjeras tiene respecto de su situación social en la provincia de Ciudad Real.

El libro se estructura a partir de tres capítulos: los movimientos migratorios actuales; Familia y cadenas migratorias y el Inmigrante en la sociedad de mercado total. La primera parte resume el principio de partida del análisis "glocal" del desarrollo sostenible, partiendo del estudio de la situación de la población extranjera en el mundo, para acabar descendiendo a lo local. La segunda parte analiza la situación de partida de los inmigrantes en nuestra provincia, las estructuras primarias de acogida, el espacio social que viaja con ellos, la llegada, modelos familiares y cadenas migratorias, así como el interés por la educación. La tercera parte se refiere a las estrategias de acogida de la población receptora, sus derechos dentro de la rígida estructura impuesta por la actual Ley de Extranjería, que los margina e ilegaliza de la estructura socioeconómica, alejándolos del mercado laboral normalizado. Su trabajo propone un nuevo modelo de consenso donde se produzca la plena participación social de los colectivos más vulnerables y en situación de exclusión social de nuestra provincia, representados por este flujo de personas de origen extranjero que entra y sale de la provincia de Ciudad Real.

Manuel Richard, siempre comprometido con los grupos sociales en situación de mayor riesgo social, habla de "indocumentados en nuestros pueblos", denuncia las situaciones de malos tratos producidas dentro del ámbito de las parejas de extranjeros “¿mujeres inmigrantes o mujeres de inmigrantes?”. El proyecto surge del seguimiento realizado por las actuaciones de Cáritas en Argamasilla de Alba, La Solana, Socuéllamos y Tomelloso, municipios de la provincia de Ciudad Real, con una significativa presencia de población inmigrante y donde participa a través de la "Conferencia sobre la Globalización". A partir de aquí, se configura un equipo de trabajo apoyado por CEDERCAM, que se encarga de la puesta en marcha del estudio sociológico que deriva en la publicación de este libro.

Para Manuel Richard, el informe sociológico "es siempre una re-construcción de la realidad, previamente de-construida por el análisis". La búsqueda de herramientas de integración social le llevó al mismo tiempo a iniciar una investigación sobre la escolarización de los hijos de inmigrantes en la provincia, fruto de su interés profesional, como Inspector de Educación en la Delegación Provincial de Educación. Este trabajo ocupó la pasión investigadora de los últimos días de Manuel y que otros sociólogos se encargarán de finalizar, como señala la cita firmada en mi libro de Inmigrantes en La Mancha, "Cadenas profesionales forman los viejos sociólogos y los nuevos pasándoles la antorcha". 
Manuel Richard supo dedicar esfuerzo y pasión por las necesidades de los hombres y las mujeres que no alcanzan los derechos sociales más elementales, convirtiéndoles en compañeros de viaje vital. Colombia le ofrece la posibilidad de trabajar con estudiantes y campesinos y a su regreso a la Universidad Complutense, continúa su extensa labor como investigador social. Publica diferentes estudios: Estudio socio-religioso de la provincia de Ciudad Real (1978); Castilla-La Mancha a lo claro (Ed. Popular, 1985); Sociología electoral de la provincia de Ciudad Real (BAM, 1985); La Formación Profesional (Ed. Popular, 1987); El espacio político. Tipología de los municipios de la provincia de Ciudad Real (BAM, 1993); Análisis de futuro de la pequeña y mediana empresa de Ciudad Real (Diputación provincial, 1997); «Transición y democracia», en la Historia de la Diputación de Ciudad Real (BAM, 1999); «Punto de debate Autonómico en Ciudad Real», en CLM: El nacimiento de una región (Biblioteca Añil, 1999). Temas que responden a un alto nivel de interés por su entorno social.

Con su colaboración directa todos hemos aprendido a conocer con mayor profundidad a nuestros vecinos, llegados allende las fronteras. Hoy como ayer seguimos estando cerca y eso es una garantía de que Manuel Richard sigue intelectualmente vivo y así lo creemos sinceramente sus compañeros de la ACMS, con quienes formó equipo y compartió desde el principio la ilusión por la Sociología en Castilla- La Mancha. "Cada hombre lleva la forma entera de la humana condición” (M. Montaigne). 